\title{
It is the glycaemic response to, not the carbohydrate content of food that matters in diabetes and obesity: The glycaemic index revisited
}

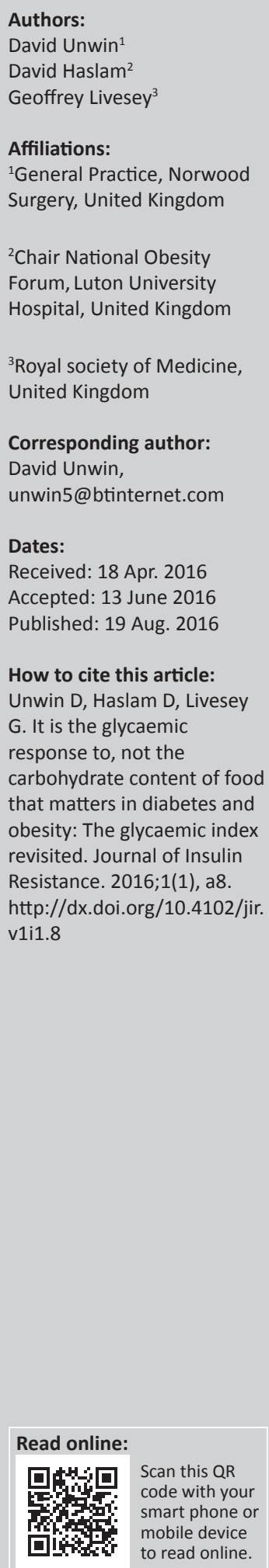

Background: The low-carbohydrate diet for diabetes and obesity is over 200 years old. A new lease of life comes with evidence for its beneficial effects supplied by research into the value of low-glycaemic index (GI) foods in diabetes control. While trialling this approach it became evident that professionals and patients had previously misunderstood the index leading to errors in food choices.

Aim: To explore the importance of the GI for those with T2D and improve understanding of the likely effect of various foods on blood glucose.

Setting: A 9000 patient United Kingdom (UK) primary care practice.

Methods: Relevant supporting studies were examined and data were reviewed from a previously published case-series with new data relating to the effect of the approach on the whole practice over a period of three years. An improved interpretation of the GI using a 'teaspoons of sugar equivalent' was developed as an aide to understanding. We looked at quality markers for diabetes and obesity such as $\mathrm{HbA1c}$ and weight.

Results: Our approach was readily understood by patients and staff, helping to achieve significant improvements in diabetes control and weight. The practice as a whole compared to the average for the area was found to have; a significantly better quality of diabetes control, lower obesity prevalence whilst spending around $£ 40000$ less per year on drugs for diabetes.

Conclusion: Greater consideration needs to be given to the harmful effects of high-GI starchy foods in the treatment and prevention of obesity and diabetes. Patient compliance and outcomes justify our approach in a primary care setting.

\section{Introduction}

There is currently substantial debate about the merits of an imminent United Kingdom (UK) tax on sugar-sweetened beverages and snacks that are high in sugar. ${ }^{1}$ The most recent Scientific Advisory Committee report ${ }^{2}$ advises a reduction of dietary sugar consumption in the UK; however, because of the furore surrounding sugar, the role of starchy carbohydrates as a source of blood sugar (glucose) has become understated, and the important role of the glycaemic index (GI) has become somewhat eclipsed. This article explains the GI as a predictor of the effect of food choices on blood glucose. We question whether higher GI carbohydrates (refined or unrefined) should also be viewed with caution in the diet and ask, for the purpose of communication with patients: can starch be viewed as a concentrated sugar?

While working in the area of dietary choices for patients with obesity and type 2 diabetes (T2D) in a primary care setting, ${ }^{3}$ we observed that many health professionals and patients when considering dietary choices were confused by the relative merits of using carbohydrate content of food in grams versus the foods' GI. Among the professionals, many erroneously assumed table sugar to affect blood glucose far more than the carbohydrate in a baked potato, for example, and others wrongly assumed that carbohydrate in different foods had a similar effect on blood glucose.

GI and glycaemic load (GL) values have been tabulated for the various carbohydrate foods. ${ }^{4}$ The position of any food in a GI or GL league table is determined by the food's effect on post-prandial blood glucose. This is determined by both the type and the amount of carbohydrates in the food and also how quickly the food can be digested. For compliance with guidelines on healthy eating, separate league tables for each food group in the guidelines can be advised. The effect of foods on 
blood glucose is indexed to a standard amount of a pure carbohydrate, a sugar or glucose. Indexing results in the foods' GI of GL values are independent of a person's ability to control blood glucose; hence, GI and GL are applicable to both healthy persons and patients with pre-diabetes or diabetes. Unfortunately, most people we encountered, including health professionals, struggled to visualise the GL in grams for a portion of a food because it was an expression with which they were unfamiliar. Furthermore, people may struggle to visualise a gram, kilocalorie or kilojoule of sugar but are generally familiar with the quantity 'a teaspoonful of sugar', which we use in our approach to visually communicate the effects of different foods on blood glucose concentrations. Thus, we considered that it may be more helpful to use the more familiar $4 \mathrm{~g}$ teaspoon of sugar as our unit of reference. The idea was that this would help patients with pre-diabetes or diabetes to understand the relative glycaemic consequences of dietary choices such as boiled rice, cornflakes and a slice of bread compared with, for example, broccoli. It is possible that a teaspoon of glucose might achieve a similar goal; however, patients perceive the importance of table sugar more readily and are without confusion about what glucose is. It should be pointed out to patients that table sugar contains fruit sugar (fructose) as well as glucose, and fructose has health concerns all of its own when consumed in excess..$^{5,6,7}$ It is not the purpose here to discuss the relative merits of fructose versus glucose about which there is a long-standing unresolved controversy; $;, 9,10,11,12$ rather, our purpose is to emphasise that high glycaemic starchy foods also have significant health concerns, ${ }^{13}$ possibly greater than for table sugar ${ }^{14}$ or saturated fats. ${ }^{15}$

In view of the confusion (described above) we encountered over the carbohydrate-related terms (GI and GL) that are used among health practitioners, we provide their derivation here.

\section{Glycaemic index}

Subsequent to an earlier study, ${ }^{16}$ David Jenkins and colleagues introduced the term 'glycaemic index' to rank the different carbohydrates in various foods by their ability to raise blood glucose after their ingestion, relative to the rise for the same amount of carbohydrate from a standard reference food, now pure glucose. ${ }^{17}$ The GI may be obtained from food tables ${ }^{4}$ or by original determination using an International Organization for Standardization standard method. ${ }^{18}$ The GI is calculated as 100 times the 2-h post-prandial blood glucose response (incremental area under the curve) to a food containing $50 \mathrm{~g}$ of carbohydrate divided by the 2-h post-prandial blood glucose response to $50 \mathrm{~g}$ glucose, each in 10 persons of normal health. If the food volume surrounding $50 \mathrm{~g}$ of the particular carbohydrate is too much to eat (as in a food with lowcarbohydrate density such as broccoli), then lower doses can be tested provided that the standard reference includes the equivalent amount of carbohydrate as glucose. The correlation between GI values obtained in persons with T2D and those in normal health is very high (0.94) so that GI values in normal persons can be used in those with diabetes. ${ }^{4}$
The high correlation also means that the GI is essentially independent of the degree of glucose intolerance from health to T2D.

An assumption among many health professionals we observed was that carbohydrate-based foods have a GI lower than that of table sugar; although this view was commonly held, it can be seen to be wrong for some common foods because the GI of table sugar (GI 65) is similar to or lower than the GI of some starchy foods, for example, basmati rice (GI 69), wholemeal bread (GI 74) and baked potato (GI 86) (see Figure 1, data column 1). This error affected food choices being recommended by health professionals and being adopted by patients. Therefore, while cutting table sugar from their diets, patients would still consume large quantities of starchy foods being unaware of the real consequences for blood glucose. GI compares foods for a standard amount of that particular carbohydrate. What health practitioners also need to take into account is the GL; this has the additional benefits of taking into account the carbohydrate content of the food and a likely portion size for any particular food eaten.

\section{Glycaemic load}

GL was introduced via epidemiological work that positively related the incidence of T2D to post-prandial increments in blood glucose from foods. ${ }^{19}$ In assessing the effect of a particular food on blood glucose, there are two important questions:

1. What is the density of carbohydrate in the food?

2. How does the particular carbohydrate in a typical portion of that food affect post-prandial blood glucose?

In talking with health professionals and patients, we abbreviated these questions about the food. It seemed to help communication, to ask about any food, saying:

1. How carby is it? (Q1)

2. How sugary is that particular carb? (Q2)

Note that the two questions investigate the total available (digestible) carbohydrate content of a serving or portion of food (g/serving) (Q1) together with the GI of the carbohydrate in the food (Q2). For health professionals, we show the calculations made for baked potato by using glucose as the reference standard (Box 1), which gives a value that nutritionists call the 'glycaemic load per serving' (with units of $\mathrm{g}$ /serving). In this case, the GL generated by $150 \mathrm{~g}$ (about $5 \mathrm{oz}$.) of baked potato is shown to be equivalent to $22 \mathrm{~g}$ of pure glucose, which is important information, especially for someone with diabetes. The epidemiological work on incident T2D initiated by Salmeron et al. ${ }^{19,20}$ has now been expanded to 24 studies worldwide, for which meta-analyses reveal a strong dose-response T2D-GL relation, ${ }^{21}$ implying with support of interventional studies ${ }^{13}$ that diets lower in GL can be preventative of T2D. The GL per standard serving of food item also varies (Figure 2). 


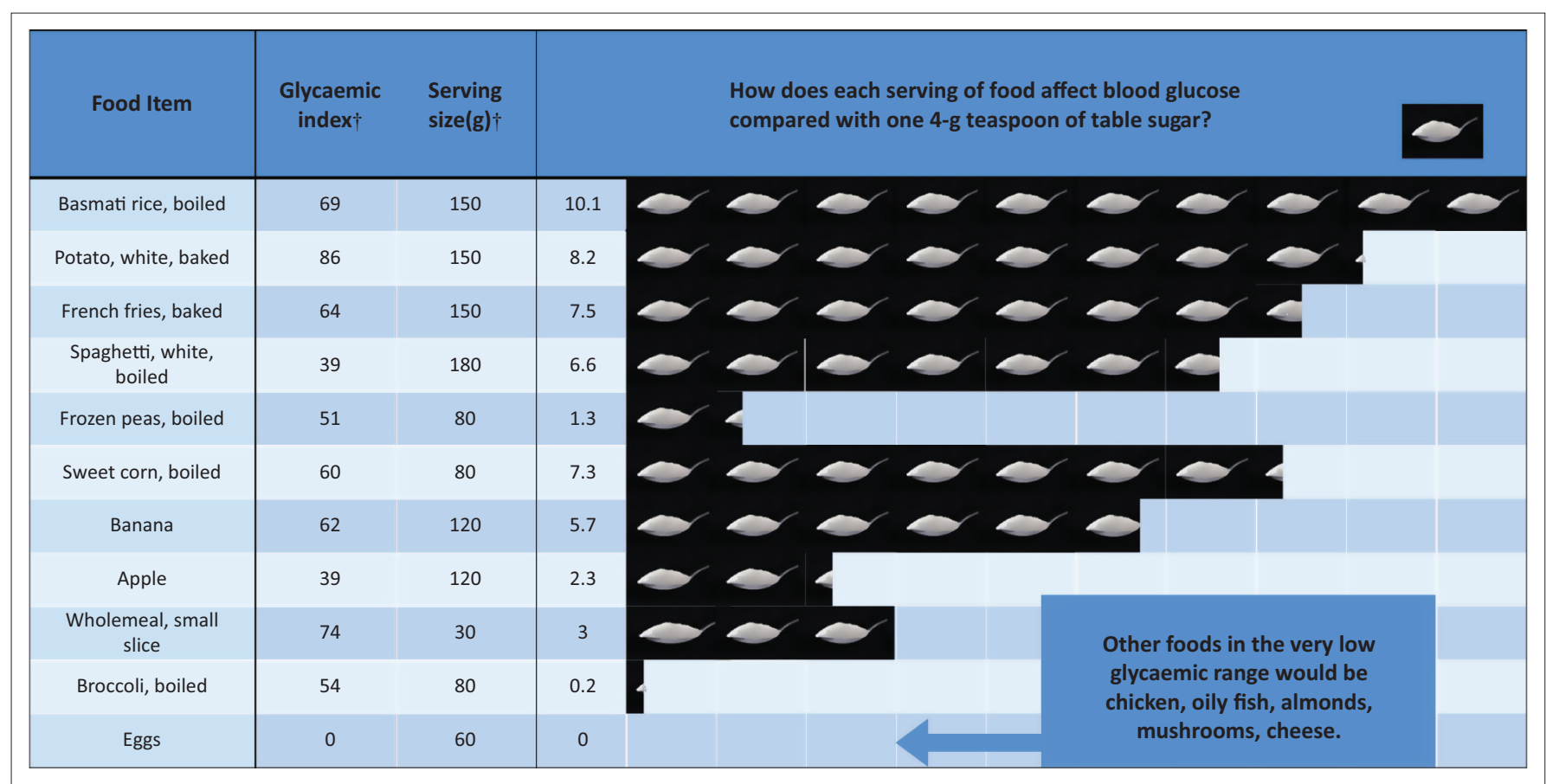

Source: Atkinson FS, Foster-Powell K, Brand-Miller JC. International tables of glycemic index and glycemic load values: 2008. Diabetes Care. 2008;31(12):2281-2283. http://dx.doi.org/10.2337/dc08-1239 Table A1 where the index is greater than zero or for broccoli, which is approximated based on available carbohydrate compostion.

FIGURE 1: An improved version of the infographic shared with health professionals to show how the glycaemic index helps inform dietary choices.

BOX 1: Worked example calculation of glycaemic load.

\section{For a baked potato weighing $150 \mathrm{~g}$ : \\ How carby is it? It has $17 \mathrm{~g}$ carb* per $100 \mathrm{~g}$, so $17 \times 150 / 100=25.5 \mathrm{~g}$ of potato carbohydrate. \\ How sugary is the carb? It has a Gl of 86 , so $25.5 \times 86 / 100=22 \mathrm{~g}$ glycaemic load in the $150 \mathrm{~g}$ serve size of potato. \\ *, Where carbohydrate weight is expressed as the monosaccharide (glucose) equivalent weight as in the UK food tables. \\ Carb, carbohydrate; GI, glycaemic index. \\ Communicating glycaemic load as teaspoonful of a familiar carbohydrate}

For this purpose, we use table sugar as the familiar carbohydrate. In an earlier version of Figure 1, glucose was used by the Norwood Surgery to demonstrate to several hundred patients the effects of standard portions of various foods on blood glucose and was also piloted with a group of 20 doctors. Many found it very difficult to believe that the figure's data were correct because they thought sugar would have a greater effect on the blood glucose response than that produced by most starchy foods. It was also evident that patients were unfamiliar with and confused by pure glucose as the benchmark, being far more accustomed to 'table sugar' in daily use.

A teaspoonful of sugar was thought easier for patients to visualise than the equivalent of pure glucose, and hence the updated depiction of Figure 1. For health professionals, we show the calculations for brown bread (wholemeal) in Box 2 as an example. Firstly, the steps in Box 1 are followed for both the brown bread and the table sugar (given in Box 2). Then, the GL ( $\mathrm{g} /$ per serving) of the brown bread is re-expressed by dividing by the GL of a $4-\mathrm{g}$ serving of table sugar (one teaspoonful). In this way, it can be seen that a small slice ( $30 \mathrm{~g})$ of wholemeal

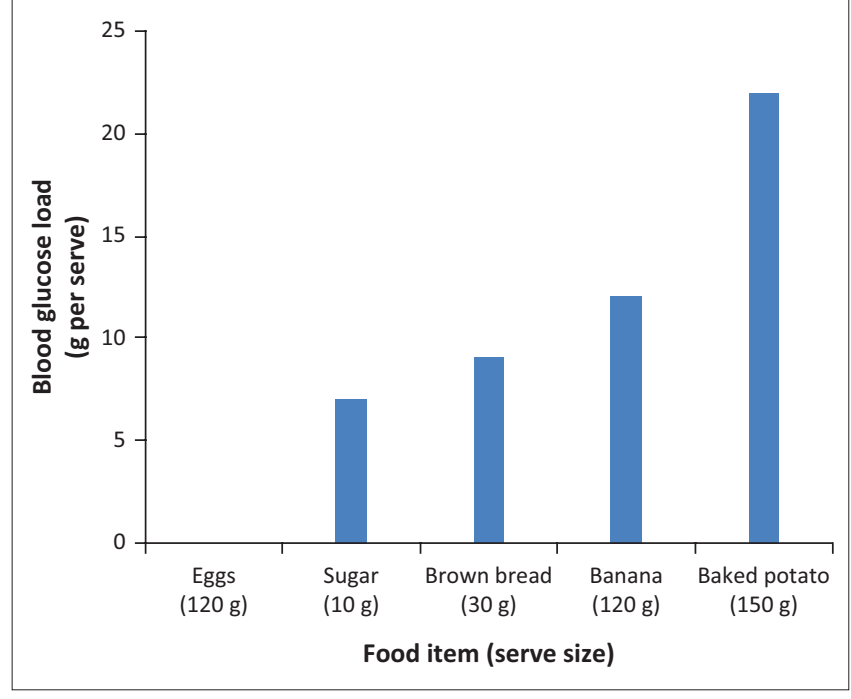

Source: Atkinson FS, Foster-Powell K, Brand-Miller JC. International tables of glycemic index and glycemic load values: 2008. Diabetes Care. 2008;31(12):2281-2283. http://dx.doi.org/10.2337/ dc08-1239

Data are from the International tables of glycaemic index and glycaemic load.

FIGURE 2: Blood glucose load* per serve size of food item ( ${ }^{*}$ glycaemic load = GI $\times$ carbohydrate amount $g$ per serve/100). Sugar is table sugar consumed in water as a drink.

bread is equivalent to more than three teaspoons of table sugar in terms of resultant blood glucose response - again which is important information for someone with diabetes.

Figure 1 shows that the teaspoonful of table sugar equivalents for GL per serving varies considerably between some common foods, with values ranging from 0.2 teaspoons for broccoli to an alarming 10.1 teaspoons of sugar for a portion of basmati rice. Our first question (how carby is it?) explains why a food like broccoli with a moderately high-GI of 54 has little actual effect on blood glucose (Figure 1); it is because the blood glucose 
response depends on the density of carbohydrates in the food and the amount of carbohydrates in broccoli is very low, the food being largely water. Therefore, for broccoli, the blood glucose response is very low, and almost independent of the food's high-GI. However, for foods containing a lot of carbohydrates (e.g. 'starchy' foods), the resultant postprandial blood glucose response strongly depends on the carbohydrate's GI - it is these foods that have the potential for harm, particularly for those with obesity and diabetes.

\section{Method: High glycaemic index carbohydrate-restricted diets at the Norwood Surgery}

A carbohydrate-restricted diet in diabetes therapy has the main objective of reducing patient exposure to too high a

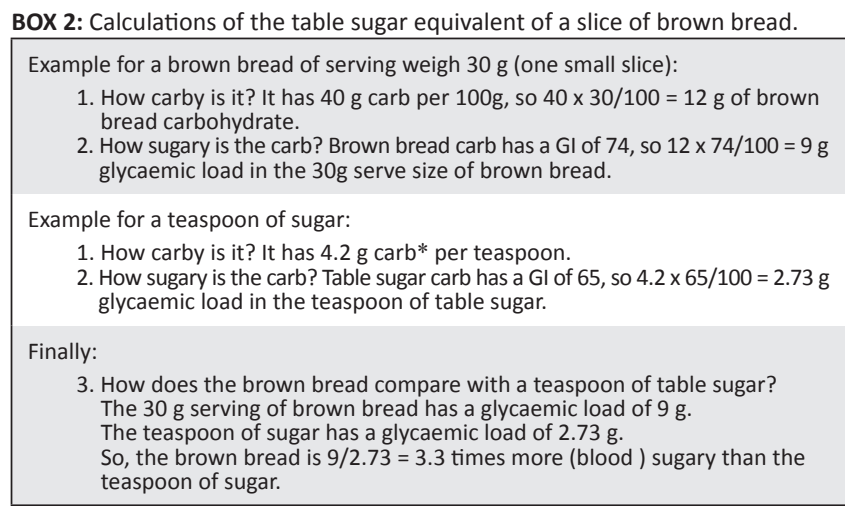

*, One might assume $1 \mathrm{~g}$ sucrose yields $1 \mathrm{~g}$ carbohydrate as monosaccharide (glucose) equivalent weight but it yields $1.05 \mathrm{~g}$ equivalents. This is why in Figure 2 the $10 \mathrm{~g}$ of sucrose has a glycaemic load of 7 and not 6.5 .

Carb, carbohydrate; Gl, glycaemic. post-prandial blood glucose response to carbohydrate foods. ${ }^{22}$ This is achieved with a low-carbohydrate diet, which has been defined as one supplying $\leq 130 \mathrm{~g}$ carbohydrate a day. A long history of research led to a scientific case for their adoption in diabetes and obesity therapy (Box 3). At the Norwood Surgery, a UK suburban practice with over 9000 patients, of whom 850 had diabetes or pre-diabetes, exposure to post-prandial blood glucose was reduced with the aid of a pamphlet 'So what should I eat to control Diabetes or Pre-diabetes?'23; the pamphlet was used without weighing food or calorie counting, but it recommended 'reduce starchy or sugary foods ... if possible cut out bread, pasta, potatoes, rice ... and sugar ... and also cakes and biscuits' which are all higher or high-GI foods. An infographic 'teaspoons of sugar' was used to aid patient understanding of the glycaemic consequences of their food choices (Figure 1). As an example, this includes banana among foods to cut out (a single ripe banana is equivalent to 5.7 teaspoons of sugar). Green vegetables, salads, tomatoes, onions, berries such as blueberries, raspberries and strawberries, and nuts were to be eaten freely as they were low in carbohydrate; however, tropical fruits often with either higher GI or higher GL (e.g. banana [already mentioned], mangoes and pineapple) were to be cut. The pamphlet also included advice on other food groups such as dairy, meat, fish, nuts and healthy fats.

The 69 study subjects had abnormal liver function, diabetes or impaired glucose tolerance and were selected opportunistically from patients at the Norwood Surgery. Advised to consume diets according to their pamphlet, they were given regular feedback, often in graphic form of the

BOX 3: A history of sugar and carbohydrate restriction in diabetes and health.

Prior to $\mathbf{1 7 7 6}$ Diabetes had been widely considered to be a disease of the kidneys, best treated by replacing the sugar lost in the urine (tested by the urine's sweetness), with increased sugar in the diet - a regime which sounds ludicrous today.

1776 Matthew Dobson, a Liverpudlian physician, went a step further; he noticed that blood tasted sweet, too; thus, he discovered hyperglycaemia and realised that the metabolic fault occurred prior to the kidneys.

1797 Carbohydrate-restricted diets seem to have entered the consciousness of the medical profession in this year when John Rollo, ${ }^{a}$ a Scottish physician to the Army, entered the debate surrounding the character and management of type 2 diabetes. Rollo, by boiling down urine to sugar, found that if the obese ( 232 pounds or $105 \mathrm{~kg}$ ) Captain Meredith ate debate surrounding the character and management of type 2 diabetes. Rollo, by boiling down urine to sugar, found that if the obese (232 pounds or $105 \mathrm{~kg}$ ) Captain Meredith ate
less 'farinaceous' (starchy) food, less urinary sugar was produced. Hence, Rollo pioneering a low-carbohydrate dietary approach, which eliminated frequent urination, reversed less 'farinaceous' (starchy) food, less urinary sugar was produced. Hence, Rollo pior
elevated sugar in both blood and urine and led to the loss of excess body weight.

1848 Claude Bernard, a renowned physiologist, investigates the role of the liver in blood sugar production, and dietary starches in particular, which both affect the milieu interieur (homeostasis) in diabetes.

1863 William Banting, a relative of the Nobel Prize winner Frederick Banting, wrote the first commercial diet. His 'Letter on Corpulence Addressed to the Public' ${ }^{\prime}$ promoted the low-carbohydrate approach. Prior to this, Banting had become so obese that he was unable to tie his shoelaces and was forced to walk downstairs backwards to ease the pressure on his knees. By the age of 65 when he weighed $202 \mathrm{lbs}(92 \mathrm{~kg})$ and hearing loss added to his co-morbidities, he consulted 'the celebrated aurist' William Harvey, who serendipitously had recently attended a lecture in Paris by Claude Bernard. Harvey, using Banting as his 'guinea pig', advised him to cut all starchy food from his diet, which had a dramatic effect, inducing a weight loss of over 3 stone $(19 \mathrm{~kg})$, accompanied by a transformation in his health

1863-1956 Throughout the 19th and early 20th centuries, a reduced carbohydrate diet was considered to be the standard therapy for both diabetes and obesity and was recognised and taught by such eminent physicians as Nathan Smith, ${ }^{,}$James Salisbury, ${ }^{\mathrm{e}}$ Frederick Allen, ${ }^{\mathrm{f}}$ Elliott Joslin, ${ }^{\mathrm{g}}$ Alfred Pennington, ${ }^{\mathrm{h}}$ and Raymond Greene. ${ }^{\mathrm{i}}$

1956 In highly controversial studies, ${ }^{j}$ Ancel Keys published, ${ }^{k}$ on cholesterol and heart disease. ${ }^{1}$ This overturned the prevailing idea about diet, which gave rise to low-fat diets as being beneficial, and arguably laid the foundation of the current obesity and diabetes epidemic. Only now is the low-carbohydrate dietary approach returning to prominence in dietary therapy for diabetes.

a, Rollo J. An Account of Two Cases of the Diabetes Mellitus. London: Dilly; 1797.

b, Bernard C. De l'origine du sucre dans l'économie animale. Archives Générales de Médicine. 1848;18:303-319.

c, Banting W. Letter on Corpulence Addressed to the Public. London: Harrison; 1863.

d, Lee A, Witters, MD, Luciano M, Williams C, Yang J. Diabetes Detectives. Dartmouth Medicine. 2008;3(2).

e, Salisbury JH. The Relation of Alimentation and Disease. London: Vail; 1988.

f, Allen F, Stillman E, Fitz R. Total Dietary Regulation in the Treatment of Diabetes. New York: The Rockefeller Institute for Medical Research; 1919.

g, Joslin E. A diabetic manual for the mutual use of doctor and patient. Philadelphia: Lea and Febiger; 1918.

h, Pennington AW. Treatment of Obesity with Calorically Unrestricted Diets. Am J Clin Nutr. 1953;1:343-348.

i, Greene R. The Practice of Endocrinology. Philadelphia, Lippincott; 1951.

j, Teicholz N. The Questionable Link Between Saturated Fat and Heart Disease. Wall Street J. 2014. Available from http://www.wsj.com/articles/SB10001424052702303678404579533760760481486.

k, Keys A (ed). Coronary heart disease in seven countries. Circulation. 1970;41(4 Suppl):1-200. 
results of their bimonthly blood tests and also weight and blood pressure (BP).

In addition to the case study group the approach was rolled out as an option to the total practice population via the practice nurses and partners. Of the practice population six went on the low carb diet themselves. This was done not only on an individual basis but also via our regular evening group sessions which included any interested relatives.

\section{Results}

\section{Outcomes from the Norwood Surgery Study}

Compliance to the dietary advice was evident as 68 of 69 patients beginning the study completed an average of 13 months dietary treatment. ${ }^{3}$ Patient satisfaction with the diet was high from reports of feeling better and having more energy. Mean body weight fell by $9.0 \mathrm{~kg}(p<0.001)$, waist circumference fell by $15 \mathrm{~cm}(p<0.0001)$, blood glucose control measured as $\mathrm{HbA}_{1 \mathrm{c}}$ fell by $10 \mathrm{mmol} / \mathrm{mol}$ or $19 \%(p<0.001)$, liver function measured as serum glutamyl transferase improved by $39 \%(p<0.001)$ and cholesterol fell by $5 \%(p<$ 0.001). Systolic and diastolic BPs dropped significantly too ( $p$ $<0.005$ ). Plasma triglycerides were not measured, but in common with prior observations for low-carbohydrate diets a significant improvement would have been anticipated. ${ }^{22}$

Dietary advice to avoid, so far as possible, common higher GI carbohydrate foods rather than only sugar or any carbohydrate food has continued now for over 3 years at the Norwood Surgery. In addition to the published study results noted above, significant practice-wide improvements occurred:

1. Diabetes drug spend is down, now saving approximately $£ 45000$ (\$65 000) per year against the regional average, and represents the lowest spend per 1000 patients in any of the 19 surgeries in the surrounding Southport (UK) and Formby area for which information was available (Figure 3). This saving should be seen against the extra costs of the Norwood Surgery diabetes intervention at just under $£ 9000$ (\$13 000) per year.

2. Obesity prevalence at Norwood Surgery based on body mass index (BMI) is down too (Quality and Outcome Framework figures for England 2012-2015). Before the study, the prevalence was $9.4 \%$ at Norwood, which has now dropped to $8.4 \%$. This compared to the figures for England as a whole where the prevalence is now $9.0 \%$.

3. Overall practice markers for diabetes control have also improved: nationally, the English primary care Quality and Outcome Framework marker of successful diabetic control is an $\mathrm{HbA}_{1 \mathrm{c}}$ of $\leq 59 \mathrm{mmol} / \mathrm{mol}$. Previously, $59.6 \%$ of our patients met this target, and now $65.4 \%$ of patients do so, an improvement of $5.8 \%$. This is against an average achievement of $60.4 \%$ for England.

\section{Discussion}

It is now de rigueur to display cubes of sugar in front of fizzy drinks at diabetes conferences to represent their vast sugar content, whereas the effect of, for example, brown bread (whole grain) on blood sugar is trivialised: we may hear 'there is hardly any sugar in bread' and 'it is a good source of

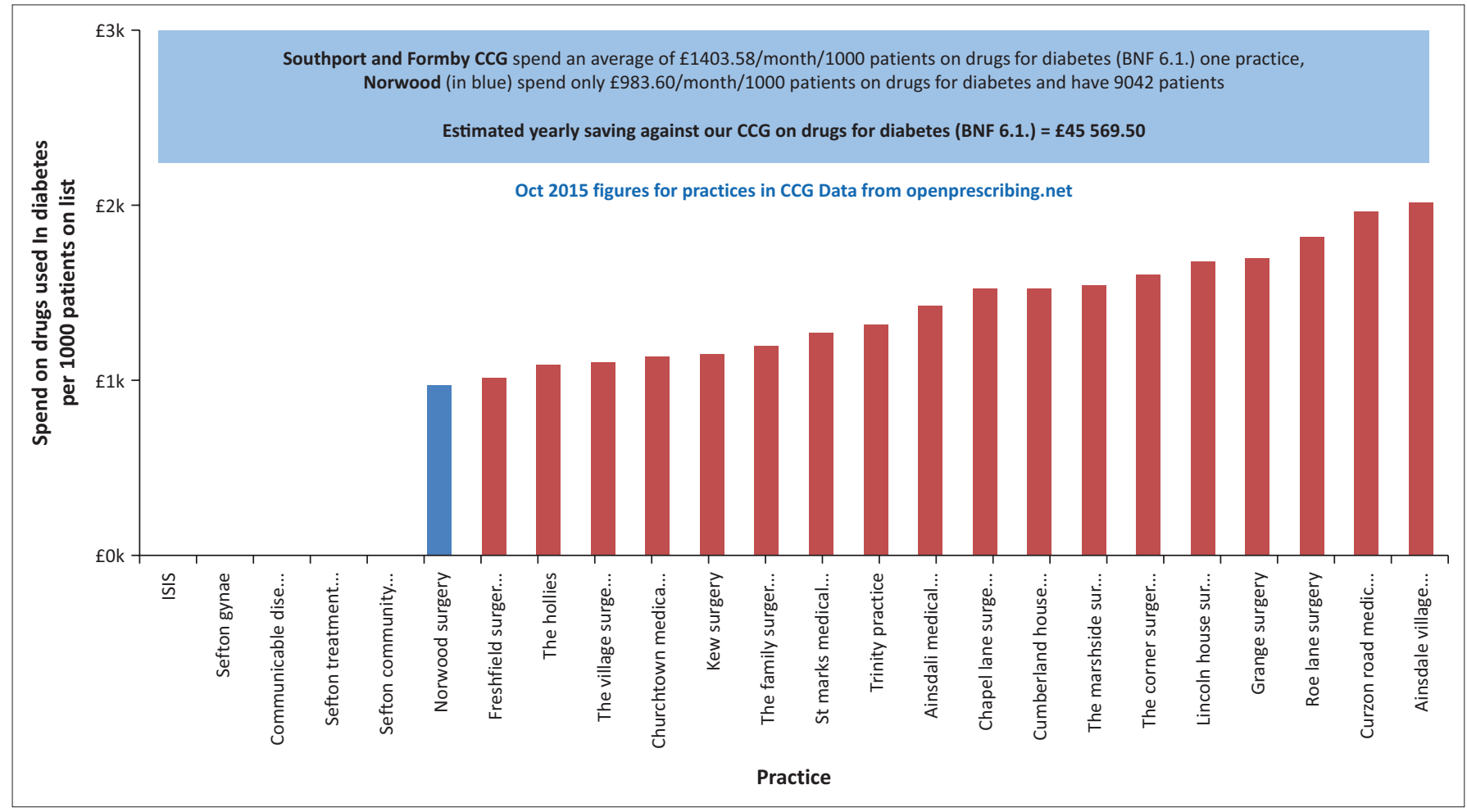

Source: OpenPrescribing.net Ben Goldacre and Anna Powell Smith 2015

FIGURE 3: Norwood surgery spends the least in Southport and Formby CCG on drugs for diabetes. 
energy for people with diabetes'. However, higher GI staples are a significant source of blood sugar ${ }^{4}$ and data we report from our primary care setting suggest that these staples are neither a good source of energy for diabetes and pre-diabetes patients nor helpful in curtailing expenditure on drugs for diabetes. It is a matter of concern that poor understanding of GI by doctors and health care professionals has led us to underestimate the importance of knowing the different glycaemic effects of various carbohydrates foods. Although all fruits may be recommended for health improvement, it is noteworthy that those with lower GI are preferable to those with higher $\mathrm{GI}$ in diabetes patients, lowering $\mathrm{HbA}_{1 \mathrm{c}^{\prime}} \mathrm{BP}$ and coronary heart disease risk, ${ }^{24}$ and even among persons adherent to a diet considered healthy (e.g. the Mediterranean diet); those consuming a lower GL diet are at lower risk of diabetes. ${ }^{25}$

We recommend that dietary starch should be considered to be the equivalent of concentrated glucose; indeed, starches comprise condensed molecules of glucose. In the Norwood primary care practice, this knowledge helps general practitioners, health care professionals and patients to understand that starches are a significant source of blood glucose. Moreover, people generally eat equally as much, and often more, carbohydrate from starchy foods as from sugary foods and drinks; therefore, there should arguably be equal or more concern about the starchy foods we eat. A possible flaw in the table sugar equivalent system we trialled was that patients might increase dietary sucrose perceiving it less of a threat than say bread. In practice, this was not a problem because all those joining the program had as their first priority the elimination of table sugar from their diets. This addresses the point that dealing with glycaemia is only one aspect of the complex goal of improving diet, others being possible nutrient dilution in an energy-restricted diet, and also the controversial dangers of fructose as noted above.

A suggested criticism of the GI is that it is 'unreliable' because the index depends on how food is prepared. Thus, raw or unground foods have a less effect on blood glucose compared to cooked or ground foods. But turning this around, this is the information that would be really helpful to someone with diabetes or obesity, when used in the present dietary context.

A further criticism of GI is that it is confusing for patients practising carbohydrate exchange if they are not familiar with glucose or the GI and their education on these in primary care is unsatisfactory. However, by using GI and therefore deriving GL and expressing the value in terms of teaspoons of table sugar, which is more familiar to patients, they may be successful in taking control of their diabetes. The level of control in the Norwood patients would be unexpected if patients were confused or non-compliant. Moreover, because the objective is to lower the patient's GL by including restriction on high-GI carbohydrate staples, there is no precise target to achieve, such as those practised in scenarios demanding carbohydrate exchange which is easier to combine with family life as there is no weighing of food in this approach.

Besides improvement in body weight and diabetes markers, the cost savings attributed to the lower GI, lower carb dietary pamphlet and motivational support described are substantial. The patients' diet was well tolerated whereas drugs for diabetes, which we find so many patients can avoid, may have questionable efficacy. ${ }^{26}$ Also patients often can be intolerant to widely used drugs, for example, metformin. ${ }^{27}$ Dietary treatment allows patients to take control of themselves; by contrast drug treatment inevitably leaves the patient dependent on the health service, with many having to face these drug-related problems.

The improved outcomes (discussed above) were achieved in the Norwood study partly by reducing sugar in the diet and partly by counselling both patients and health care professionals in the team about the effect of eating certain (higher GI) starchy foods on blood glucose and body weight. For example, the effect of bread or rice is just as great as the more readily understood effect of sugary foods. But as already mentioned, this message was better understood when translated into teaspoons of table sugar as shown in Figure 1.

It is likely that better patient motivation also assisted the improved outcomes in the Norwood study group $(n=68)$ and practice-wide ( $n=850$ diabetic and pre-diabetic patients). This was augmented by handing out individual results of patients' progress in the form of graphs on a bimonthly basis.

The patients in the Norwood Surgery study with impaired glucose tolerance and $\mathrm{T} 2 \mathrm{D}$ experienced a reduction in $\mathrm{HbA}_{1 \mathrm{c}^{\prime}}$ which can be explained in good part by reductions in dietary exposure to GL through manipulation of $\mathrm{GI}^{28}$ or carbohydrate $\operatorname{load}^{22}$ or both together. This not only indicates improved glycaemic control but also suggests reduced risks for complications, cardiovascular disease and mortality. ${ }^{29,30,31}$

The dietary concept applied at Norwood is possibly applicable to persons using insulin pumps or injections. Patients with type 1 diabetes (T1D) consuming lower GI diets have better blood glucose control (as judged by $\mathrm{HbA}_{1 \mathrm{c}}$ ) than those consuming higher GI carbohydrates. ${ }^{32}$ Also, T1D patients on low-carbohydrate diets have shown improved stability of glycaemic control and reduced number and severity of hypoglycaemic episodes while allowing less error in matching insulin requirements to carbohydrate intake. ${ }^{33}$ Lowering the insulin requirement would also lower the risk of exogenous insulin-related weight gain.

The majority of patients at the start of the Norwood study were overweight or obese (mean body weight $100 \pm 16 \mathrm{~kg}$ and waist circumference $120 \pm 10 \mathrm{~cm}$ ); the body weight and 
waist reductions found therefore applied to this class of patients once glucose intolerance was evident. The weight reduction in the primary care setting achieved by the Norwood study is in agreement with the weight reduction by both lowering of dietary GL as reported from meta-analysis of intervention studies ${ }^{28}$ and lowering of carbohydrate intake as reported from narrative review. ${ }^{22}$

The Norwood Study found greater lowering of waist circumference (less than 15\%) than body weight (less than $9 \%$ ). In agreement, other studies indicate that exposure to diets with higher GI carbohydrate can elevate abdominal or visceral adiposity. ${ }^{34,35,36,37,38}$ These findings make an important point that body weight and BMI $\left(\mathrm{kg} / \mathrm{m}^{2}\right)$ may not be sensitive to moderate abdominal fat accumulation when accompanied by muscle wasting. There is no doubt about the significance of threat that obesity poses to health. The risks of metabolic complications are substantially increased 'in men with a waist measurement $>102 \mathrm{~cm}$ ' and 'in women with a waist measurement $>88 \mathrm{~cm}^{\prime} \cdot{ }^{39}$ Moreover, reduction of visceral obesity is accompanied by normalisation of insulin secretion and hepatic insulin sensitivity ${ }^{40}$ which are hallmarks of T2D.

We feel that our lower carb approach is arguably applicable to the general population. Impaired glucose tolerance and obesity are increasingly prevalent worldwide. There is strong evidence from comprehensive meta-analyses of prospective cohort studies that lower exposure to dietary GL reduces the risk of incident T2D in both men and women independently of dietary or cereal fibre intake, ${ }^{21,41}$ likewise for GI with similar strength (Livesey et al., in press), and likewise too for a low-carbohydrate diet score in women. ${ }^{42,43}$ Even among non-diabetic populations, high-GI carbohydrate (starchy) food consumption is associated with a higher risk for developing T2D compared with sugar, whereas lower GI is associated with a lower risk. ${ }^{14}$ Worryingly, too, a study ${ }^{15}$ has shown that higher GI carbohydrates associate with a higher risk for myocardial infarction compared with saturated fat, whereas low-GI carbohydrate gave a lower risk. Finally, a recent consensus summit and review indicated that lower GI, GL and glycaemic response might also reduce the risk of acquiring several different cancers. ${ }^{13,44}$

Consuming too many higher or high-GI starchy staples does not appear to be good for people in the general population, particularly so for obese, T2D and pre-diabetes patients. We consider this is linked to higher or rapid rates of glucose absorption and the consequential higher blood glucose levels after digestion.

\section{High-GI starchy food: A probable spoiler of predicted health and economic benefits of recently issued dietary guidelines}

Reducing the consumption of sugar alone leaves patients and the general public still at risk of exposure to high-GI starchy foods; this is especially for the large proportion (approximately 50\%) of the population who are overweight, obese, glucose intolerant or diabetic, and likely too for persons of normal body weight (Livesey et al., in press). This problem is likely to be exacerbated by dietary guidelines that recommend the replacement of energy from sugar by starch, ${ }^{1,2}$ including their adoption in the new Eatwell Guide; ${ }^{45}$ this is because a large proportion of starchy food eaten is of high-GI, which appears harmful compared with sugar (other than in drinks with which starch is essentially incompatible unless hydrolysed to maltodextrin, which is also high in GI and possibly also harmful compared with sugar). Notably too, recent verbal suggestions to lower alcohol consumption to zero to maximally reduce the risk of cancers rather than follow proposed guidelines ${ }^{46}$ may leave individuals at greater risk of metabolically related disease because of the present level of consumption of high-GI starches. This arises because moderate alcohol consumption attenuates the risk of T2D arising from diets high in GL, whereas zero intake may double the risk of both diabetes, ${ }^{47}$ and possibly other conditions (e.g. coronary heart disease) ${ }^{44}$ that are related to high-GI starch consumption. For these two reasons, it is possible that recent dietary guidelines issued by Public Health England (PHE) $)^{1,45}$ based on the work of Scientific Advisory Committee on Nutrition ${ }^{2}$ will not be as effective for combating the joint epidemic of obesity and T2D as the PHE believes - high-GI starchy foods being the spoiler of the good intentions behind the guidelines.

Most of the evidence of harm from high-GI starchy staples was unavailable in 1991 when the Committee on Medical Aspects of Foods ${ }^{48}$ of the Department of Health of the United Kingdom was unable to find evidence of harm from starches. The lack of evidence has allowed dietary guidelines to include in their advice that energy needs not met by guideline amounts of protein, and fat (and alcohol), should be made up by starch. This position is no longer tenable. It is clear to us that high-GI carbohydrate foods are a societal problem in urgent need of resolve (Table 1).

\section{Acknowledgements Competing interests}

The authors declare that they have no financial or personal relationships which may have inappropriately influenced them in writing this article.

\section{Authors' contributions}

D.U. was the project leader. D.H. and G.L. made conceptual contributions, particularly from the wider 'world' of carbohydrates. G.L. produced the expertise and calculations to work out the 'teaspoon of sugar' equivalents. The historical perspective was prepared by D.H. Tables were conceived by D.U. Data in the tables and figures were mostly the work of G.L. 
TABLE 1: Glycaemic load of some standard food portions as $4 \mathrm{~g}$ table sugar equivalents.

\begin{tabular}{|c|c|c|c|c|c|}
\hline Food item & $\begin{array}{l}\text { GI from scientific } \\
\text { literature }+, *\end{array}$ & $\begin{array}{l}\text { Serving size } \\
\text { (g) }\end{array}$ & $\begin{array}{l}\text { Available carbohydrate content } \\
\text { (g/serve) } \Phi\end{array}$ & $\begin{array}{l}\text { Glycaemic load } \\
\text { (g/serve) }\end{array}$ & $\begin{array}{c}\text { How does this food compare with } \\
\text { a 4-g teaspoon of sugar? }\end{array}$ \\
\hline Greek-style yogurt & 12 & 200 & 8 & 1 & 0.4 \\
\hline Milk, full-fat & 46 & 250 & 12 & 5 & 2.0 \\
\hline Digestives biscuit plain & 39 & 25 & 16 & 6 & 2.3 \\
\hline Basmati rice white boiled $8 \mathrm{~min}$ & 69 & 150 & 40 & 28 & 10.1 \\
\hline Couscous, rehydrated with hot water & 65 & 150 & 14 & 9 & 3.3 \\
\hline Cornflakes & 93 & 30 & 25 & 23 & 8.5 \\
\hline Branflakes & 50 & 30 & 20 & 10 & 3.7 \\
\hline Tomato raw $\ddagger$ & $54 \%$ & 50 & 1.6 & 0.24 & 0.3 \\
\hline Mushrooms $\ddagger$ & $70 \%$ & 80 & 0.3 & 0.03 & 0.1 \\
\hline Cauliflower & 60 & 80 & 3.2 & 0.32 & 0.7 \\
\hline French fries baked $15 \mathrm{~min}$ & 64 & 150 & 32 & 21 & 7.5 \\
\hline Pea, frozen, boiled & 51 & 80 & 7 & 4 & 1.3 \\
\hline Sweet corn boiled & 60 & 80 & 18 & 11 & 4.0 \\
\hline Apple, Golden Delicious & 39 & 120 & 16 & 6 & 2.3 \\
\hline Spaghetti white boiled (France) & 39 & 180 & 46 & 18 & 6.6 \\
\hline
\end{tabular}

$\dagger$, From Atkinson, F. et al. (2008). International tables of glycemic index and glycemic load values: 2008. Diabetes Care 31(12): 2281-2283, Table A1, except were approximated.

$\$$, Values for these foods are derived from UK Food Composition Tables, with GI calculated at INLogic Ltd on the basis of detailed carbohydrate composition; these values are likely to be overestimated.

I, Weights of available carbohydrate (defined as digested and absorbed carbohydrates) are the monosaccharide equivalent weights, for example, $4 \mathrm{~g}$ of sucrose yields $4.2 \mathrm{~g}$ of a glucose-fructose mixture (and $1 \mathrm{~g}$ of starch yields $1.10 \mathrm{~g}$ of glucose).

\section{References}

1. Public Health England. Sugar Reduction. The evidence for action [serial online] London: Public Health England; 2015 [cited 2016 Feb 5]. Available from: https:// www.gov.uk/government/uploads/system/uploads/attachment_data/ file/470179/Sugar_reduction The evidence_for_action.pdf

2. Scientific Advisory Committee on Nutrition. Carbohydrates and health [seria online]. London; 2015 [cited 2016 May 5]. Available from: https://www.gov.uk/ government/uploads/system/uploads/attachment_data/file/445503/SACN Carbohydrates_and_Health.pdf

3. Unwin JD, Cuthbertson DJ, Feinman R, Sprung VJ. A pilot study to explore the role of a lowcarbohydrate intervention to improve GGT levels and HbA1c. Diabetes Pract. 2015;4:102-108.

4. Atkinson FS, Foster-Powell K, Brand-Miller JC. International tables of glycemic index and glycemic load values: 2008. Diabetes Care. 2008;31(12):2281-2283. http://dx.doi.org/10.2337/dc08-1239

5. Chiavaroli L, de Souza RJ, Ha V, et al. Effect of fructose on established lipid targets: A systematic review and meta-analysis of controlled feeding trials. J Am Heart Assoc. 2015;4(9):e001700. http://dx.doi.org/10.1161/JAHA.114.001700

6. Livesey $\mathrm{G}$. Is there really a link between diabetes and the ingestion of fructose. Nutr Bull. 2014;38:337-343. http://dx.doi.org/10.1111/nbu.12045

7. Livesey G, Taylor R. Fructose consumption and consequences for glycation plasma triacylglycerol, and body weight: Meta-analyses and meta-regression models of intervention studies. Am J Clin Nutr. 2008;88(5):1419-1437.

8. Tappy L, Le KA. Health effects of fructose and fructose-containing caloric sweeteners: Where do we stand 10 years after the initial whistle blowings? Cur Diab Rep. 2015;15(8):54. http://dx.doi.org/10.1007/s11892-015-0627-0

9. Rippe JM, Angelopoulos TJ. Fructose-containing sugars and cardiovascular disease. Adv Nutr. 2015;6(4):430-439. http://dx.doi.org/10.3945/an.114.008177

10. Kolderup A, Svihus B. Fructose metabolism and relation to atherosclerosis, type 2 diabetes, and obesity. J Nutr Metab. 2015;2015:823081. http://dx.doi. org/10.1155/2015/823081

11. Johnson RJ, Segal MS, Sautin Y, et al. Potential role of sugar (fructose) in the epidemic of hypertension, obesity and the metabolic syndrome, diabetes, kidney disease, and cardiovascular disease. Am J Clin Nutr. 2007;86(4):899-906.

12. Livesey G. Epidemiology of fructose: Obesity and related health research. Crit Rev Food Sci Nutr. 2010;50(S1):26-28. http://dx.doi.org/10.1080/10408398.2010.52 6870

13. Augustin LSA, Kendall CWC, Jenkins DJA, et al. Glycemic index, glycemic load and glycemic response: An International Scientific Consensus Summit from the International Carbohydrate Quality Consortium (ICQC). Nutr Metab Cardiovasc www.sciencedirect.com/science/article/pii/S0939475315001271

14. Livesey G. Glycemic response and toleration. In: O'Donnell K, Kearsley MW editors. Sweeteners and sugar alternatives in food technology [serial online]. $2 \mathrm{nd}$ ed. Oxford: Wiley-Blackwell, 2012; p. 1-26. [cited 2015 Nov 21]. Available from: http://onlinelibrary.wiley.com/doi/10.1002/9781118373941.fmatter/summary

15. Jakobsen MU, Dethlefsen C, Joensen AM, et al. Intake of carbohydrates compared with intake of saturated fatty acids and risk of myocardial infarction: Importance of the glycemic index. Am J Clin Nutr. 2010;91(6):1764-1768. http://dx.doi. org/10.3945/ajcn.2009.29099

16. Crapo PA, Reaven G, Olefsky J. Plasma glucose and insulin responses to orally administered simple and complex carbohydrates. Diabetes. 1976;25(9):741-747. http://dx.doi.org/10.2337/diab.25.9.741
17. Jenkins DJ, Wolever TM, Taylor RH, et al. Glycemic index of foods: A physiological basis for carbohydrate exchange. Am J Clin Nutr. 1981;34(3):362-366.

18. International Standards Institute. Food products - Determination of the glycaemic index (GI) and recommendation for food classification [serial online]. ISO 26642. Geneva, Switzerland; 2010. [cited 2014 Nov 24]. Available from: http://www.iso. org/iso/home/store/catalogue_tc/catalogue_detail.htm?csnumber=43633

19. Salmeron J, Manson JE, Stampfer MJ, Colditz GA, Wing AL, Willett WC. Dietary fiber, glycemic load, and risk of non-insulin-dependent diabetes mellitus in women. JAMA. 1997;277(6):472-477. http://dx.doi.org/10.1001/jama.1997. 03540300040031

20. Salmeron J, Ascherio A, Rimm EB, et al. Dietary fiber, glycemic load, and risk of NIDDM in men. Diabetes Care. 1997;20(4):545-550. http://dx.doi.org/10.2337/ diacare.20.4.545

21. Livesey $\mathrm{G}$, Taylor R, Livesey $\mathrm{H}$, Liu S. Is there a dose-response relation of dietary glycemic load to risk of type 2 diabetes? Meta-analysis of prospective cohort studies. Am J Clin Nutr. 2013;97(3):584-596. http://dx.doi.org/10.3945/ ajcn.112.041467

22. Feinman RD, Pogozelski WK, Astrup A, et al. Dietary carbohydrate restriction as the first approach in diabetes management: Critical review and evidence base. Nutrition. 2015;31(1):1-13. http://dx.doi.org/10.1016/j.nut.2014.06.011

23. Unwin $D$, Unwin J. Low carbohydrate diet to achieve weight loss and improve $\mathrm{HbA} 1 \mathrm{c}$ in type 2 diabetes and pre-diabetes: Experience from one general practice. Pract Diabetes. 2014; 31(2):76-79.

24. Jenkins DJ, Srichaikul K, Kendall CW, et al. The relation of low glycaemic index fruit consumption to glycaemic control and risk factors for coronary heart disease in type 2 diabetes. Diabetologia. 2011;54(2):271-279. http://dx.doi.org/10.1007/ s00125-010-1927-1

25. Rossi M, Turati F, Lagiou $P$, et al. Mediterranean diet and glycaemic load in relation to incidence of type 2 diabetes: results from the Greek cohort of the populationbased European Prospective Investigation into Cancer and Nutrition (EPIC). based European Prospective Investigation into Cancer and Nutrition (EPIC).
Diabetologia. 2013;56(11):2405-2413. http://dx.doi.org/10.1007/s00125-013Diabet

26. Naci H, Lehman R, Wouters OJ, Goldacre B, Yudkin JS. Rethinking the appraisal and approval of drugs for type 2 diabetes. BMJ. 2015;351:h5260. http://dx.doi. org/10.1136/bmj.h5260

27. McCreight LJ, Bailey CJ, Pearson ER. Metformin and the gastrointestinal tract. Diabetologia. 2016;59(3):426-435. http://dx.doi.org/10.1007/s00125015-3844-9

28. Livesey G, Taylor R, Hulshof T, Howlett J. Glycemic response and health a systematic review and meta-analysis: Relations between dietary glycemic properties and health outcomes. Am J Clin Nutr. 2008;87(1):258S-268S

29. Stratton IM, Adler Al, Neil HA, et al. Association of glycaemia with macrovascular and microvascular complications of type 2 diabetes (UKPDS 35): Prospective observational study. BMJ. 2000;321(7258):405-412. http://dx.doi.org/10.1136/ bmj.321.7258.405

30. Khaw KT, Wareham $\mathrm{N}$, Luben $\mathrm{R}$, et al. Glycated haemoglobin, diabetes, and mortality in men in Norfolk cohort of European prospective investigation of cancer and nutrition (EPIC-Norfolk). BMJ. 2001;322(7277):15-18. http://dx.doi. org/10.1136/bmj.322.7277.15

31. Turner RC, Millns $\mathrm{H}$, Neil HA, et al. Risk factors for coronary artery disease in noninsulin dependent diabetes mellitus: United Kingdom Prospective Diabetes Study (UKPDS: 23). BMJ. 1998;316(7134):823-828. http://dx.doi.org/10.1136/ bmj.316.7134.823 
32. Buyken AE, Toeller M, Heitkamp G, et al. Glycemic index in the diet of European outpatients with type 1 diabetes: Relations to glycated hemoglobin and serum lipids. Am J Clin Nutr. 2001;73(3):574-581.

33. Nielsen JV, Gando C, Joensson E, Paulsson C. Low carbohydrate diet in type 1 diabetes, long-term improvement and adherence: A clinical audit. Diabetol Metab Syndr. 2012;4(1):23. http://dx.doi.org/10.1186/1758-5996-4-23

34. Oizumi T, Daimon M, Jimbu Y, et al. A palatinose-based balanced formula improves glucose tolerance, serum free fatty acid levels and body fat composition. Tohoku $J$ Exp Med. 2007;212(2):91-99. http://dx.doi.org/10.1620/tjem.212.91

35. Okuno M, Kim MK, Mizu M, Mori M, Mori H, Yamori Y. Palatinose-blended sugar compared with sucrose: Different effects on insulin sensitivity after 12 weeks supplementation in sedentary adults. Int J Food Sci Nutr. 2010;61(6):643-651. http://dx.doi.org/10.3109/09637481003694576

36. Yamori $\mathrm{Y}$, Mori $\mathrm{M}$, Mori $\mathrm{H}$, et al. Japanese perspective for lifestyle disease risk reduction in immigrant Japanese Brazilians - A double-blind placebo-controlled intervention study on palatinose. Clin Exp Pharmacol Physiol. 2007;34:S5-S7. $\mathrm{http}: / / \mathrm{dx}$.doi.org/10.1111/j.1440-1681.2007.04759.x

37. Bouche C, Rizkalla SW, Luo J, et al. Five-week, low-glycemic index diet decreases total fat mass and improves plasma lipid profile in moderately overweight nondiabetic men. Diabetes Care. 2002;25(5):822-828. http://dx.doi.org/10.2337/ diacare.25.5.822

38. De Assis Costa J, De Cássia Gonçalves Alfenas R. The consumption of low glycemic index meals reduces abdominal obesity in subjects with excess body weight. Nutr Hosp. 2012;25(4):1178-1183.

39. World Health Organisation. Obesity: Preventing and managing the global epidemic [serial online]. Geneva: World Health Organization; 2000 [cited 2015 Nov 21]. Available from: http://www.who.int/nutrition/publications/obesity/ WHO_TRS_894/en/
40. Lim EL, Hollingsworth KG, Aribisala BS, Chen MJ, Mathers JC, Taylor R. Reversal of type 2 diabetes: Normalisation of beta cell function in association with decreased pancreas and liver triacylglycerol. Diabetologia. 2011;54(10):2506-2514. http:// pancreas and liver triacylglycerol. Diab
dx.doi.org/10.1007/s00125-011-2204-7

41. Livesey $\mathrm{G}$, Taylor $\mathrm{R}$, Livesey $\mathrm{H}$, et al. Is there a dose-response relation of dietary glycemic load to risk of type 2 diabetes? Meta-analysis of prospective cohort studies [serial online]. Supplementary discussion. World Biomedical Frontiers, Diabetes. 2013 [cited 4 Jan 26.] Available from: http://biomedfrontiers.org/diabetes--may-2-1/

42. Halton TL, Liu S, Manson JE, Hu FB. Low-carbohydrate-diet score and risk of type 2 diabetes in women. Am J Clin Nutr. 2008;87(2):339-346.

43. Halton TL, Willett WC, Liu S, et al. Low-carbohydrate-diet score and the risk of coronary heart disease in women. N Engl J Med. 2006;355(19):1991-2002. http:// dx.doi.org/10.1056/NEJMoa055317

44. International Carbohydrate Quality Consortium. Glycemic index, glycemic load, glycemic response: Scientific consensus statement: Oldways, International Carbohydrate Quality Consortium [serial online]. 2013 [cited 2016 May 2] Available from: http://oldwayspt.org/programs/special-custom-programs/ glycemic-index-scientific-consensus2013

45. Public Health England. The eatwell guide [serial online]. London UK; 2016 [cited 2016 Mar 29]. Available from: https://www.gov.uk/government/publications/ the-eatwell-guide: Public Health England.

46. Department of Health. UK Cheif Medical Officers' alcohol guidelines review [serial online]. London; 2016 [cited 2016 May 2]. Available from: https://www.gov.uk/
government/uploads/system/uploads/attachment_data/file/489795/summary.pdf

47. Mekary RA, Rimm EB, Giovannucci E, et al. Joint association of glycemic load and alcohol intake with type 2 diabetes incidence in women. Am J Clin Nutr. 2011;94(6):1525-1532. http://dx.doi.org/10.3945/ajen.111.023754

48. Committee on Medical Aspects of Foods. Dietary reference values for food energy and nutrients. Department of Health. London: HMSO; 1991. 